\title{
Towards Developing the Renovation Design Guidelines for Aging Low-Cost Residential Buildings in Thailand: A Case Study of 5-Story Baan Eua Arthorn Condominium
}

\author{
Natapong Puangpinyo*, Sulawun Thanjaichon \\ Rajamangala University of Technology Tawan-OK (RMUTTO), Thailand
}

Received September 29, 2021; Revised November 26, 2021; Accepted December 13, 2021

\begin{abstract}
Cite This Paper in the following Citation Styles
(a): [1] Natapong Puangpinyo, Sulawun Thanjaichon, "Towards Developing the Renovation Design Guidelines for Aging Low-Cost Residential Buildings in Thailand: A Case Study of 5-Story Baan Eua Arthorn Condominium," Civil Engineering and Architecture, Vol. 10, No. 1, pp. 97 - 111, 2022. DOI: 10.13189/cea.2022.100109.
\end{abstract}

(b): Natapong Puangpinyo, Sulawun Thanjaichon (2022). Towards Developing the Renovation Design Guidelines for Aging Low-Cost Residential Buildings in Thailand: A Case Study of 5-Story Baan Eua Arthorn Condominium. Civil Engineering and Architecture, 10(1), 97 - 111. DOI: 10.13189/cea.2022.100109.

Copyright $@ 2022$ by authors, all rights reserved. Authors agree that this article remains permanently open access under the terms of the Creative Commons Attribution License 4.0 International License

\begin{abstract}
Nowadays, many developing countries have become aging societies that are effective for dwelling preparation in the future, especially Thailand. Thailand has entered an aging society and becomes a "Super-aged society" (Society or country with population aged 65 and over, more than $20 \%$ of the entire population) soon. These have increased the elderly housing projects of both the private and government sector, and most of the high-cost elderly housing projects in Thailand are related to incremental payback opportunities following the business investment plan [2]. The elderly housing projects for the low-cost project of the Thailand government are still not enough to demand because of an interruption in the government process for the new project. The renovation of the existing building for low cost was a simple way to solve the inequality problem of housing in an aging society. Nowadays, Thailand government still has a low-cost housing project which is Baan Eua Arthorn condominium that can be renovating existing building for the elderly. The case study research is Baan Eua Arthorn condominium project spreading all over the country with the same pattern design that can emphasize design renovation guidelines for generalized the low-cost elderly dwelling. This research focuses on the 5-story Baan Eua Arthorn condominium project that has two problems. The first problem is that a public area cannot support emergency assessment in a vertical assistance system. The second problem in the unit resident in the bathroom does not have assistive devices for
\end{abstract}

the elderly and an available area for the elderly caregiver. This study found two solutions. First, equipping a public elevator with four install options can connect to the cluster building. Second, designing area of the resident unit and adding assistive devices of the elderly and for the elderly caregivers can encourage life quality of the elderly.

Keywords Aging Society, Condominium, Low-Cost Residential, Renovate

\section{Introduction}

The elderly of the world population was rapidly increasing. That results in many countries experiencing growth in the size and proportion of older persons in their people. Expectedly in ASEAN, Thailand is ranked second in the aging society of ASEAN countries after Singapore. Population aging in Thailand has been recognized as a global demographic with continued and lasting impacts on sustainable development such as quality of life, economy, and society, especially with the basics of basic living as residential that are not concerned about aging society in the future. For high-cost elderly who have the alternative for residential as a renovation of their own house or investment in the new residential project. Thailand has a low-cost residential to support a low-cost population. 
However, it cannot keep the elderly target because the project has a limited budget and reduces construction costs. The government residential project is usually not designed to accommodate the elderly. If their renovating government residential, they will get advice from the architectural specialist about assistive devices, structure, and architecture design.

This research approach to renovate low-cost residential and solve the social inequality of the elderly problem. This study selected the Baan Eua Arthorn condominium project that is a government project for low-cost residential. Baan Eua Arthorn project was established in 2003, with 329 projects, 280,790 units (comprising condominiums, single-detached houses, twin houses, and townhouses) (Figure 1). The case study of this research selected 5-story condominiums that are elaborate renovation designs for the elderly. The design guideline of their renovation can be as the standard design of Baan Eua Arthorn condominium and convenient to use several projects for plurality the elderly population.

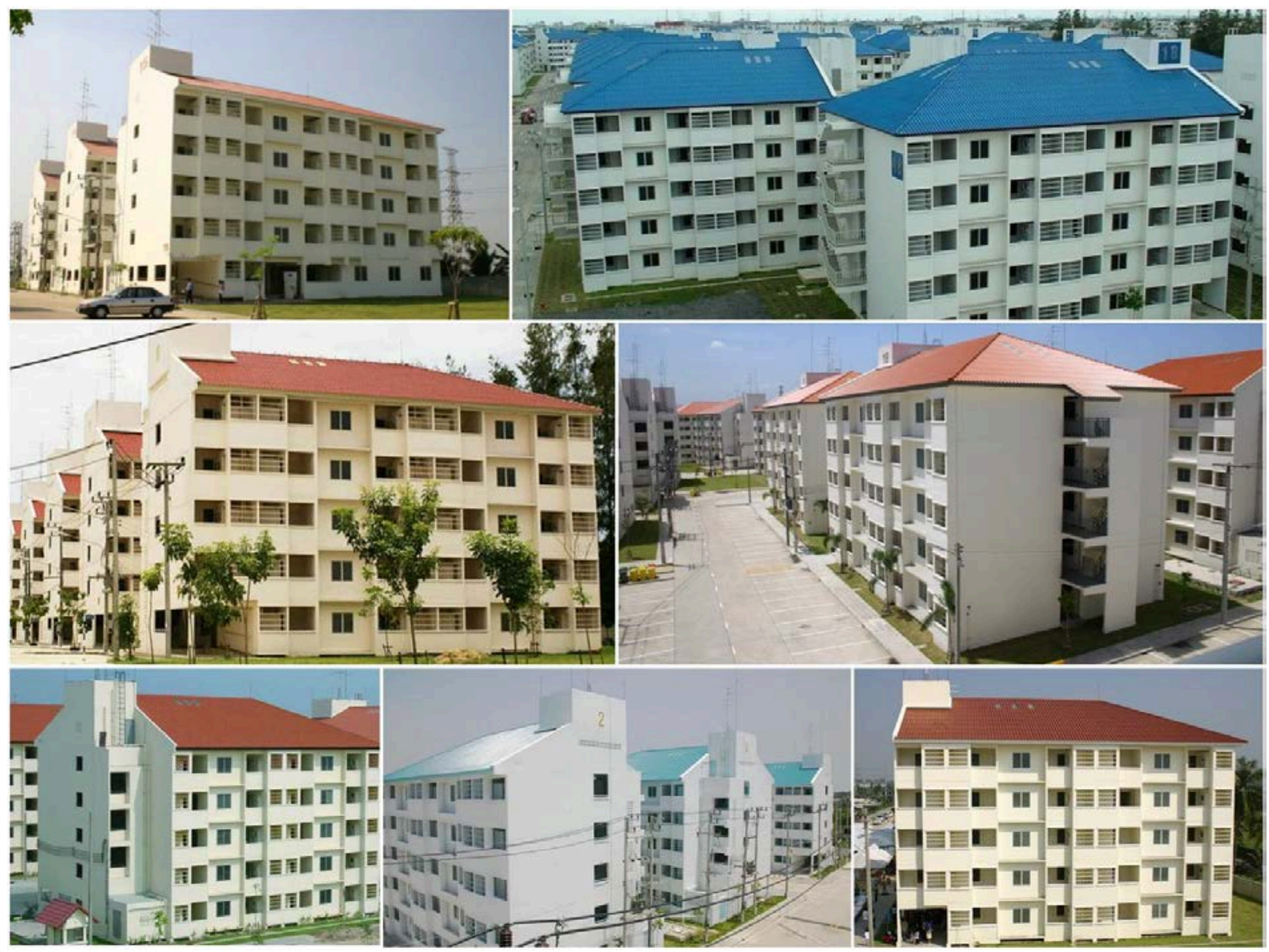

Figure 1. The 5-story Baan Eua Arthorn Condominium project in Thailand since 2003 - present 


\section{Literature Reviews}

In Thailand, the living choice for the elderly in a dedicated elderly care facility is still a costly option. But on the other hand, the low-cost residential usually take time on government process. The Knowledge Management Report of "The New Residential Development for the Elderly 2016" [3] discussed the requirements to manage the construction of facilities because many of the elderly are unhealthy and unable to help themselves. They have to require caretakers and mobility aids such as walking sticks, walking pads, wheelchairs.

The information of the elderly housing business from Kasikorn Research Center [2] presents that the current housing supply for the elderly still focuses on the upper class and luxury segments along with service level. The Investor has to require the customer as purchaser to be aged 50-55 years old and have to pre-pay that has many projects in private sectors. That process of high-cost projects is almost not impossible to low-cost projects. The low-cost target of residential usually migrated from rural to the city.

The elderly in rural areas of Thailand family prefer to stay in their initial hometown average 92\%, and the elderly in the city prefer living their initial hometown average $72 \%$ [5]. Those represent to the elderly both of them are satisfied to living with a family and are family members or co-resident can take care of them. Present, the Thai family is single-family whose few family members usually migrated to the source of the job, the elderly to move with family members. Many residents are not available for the elderly because low-cost residents are not preparing the assistive devices.

The government of low-cost residential project is "Baan Eua Arthorn" that can respond to the low-income population with a large number in the country. Baan Eua Arthorn Project was expanded to many provinces of Thailand that by the National Housing Authority. The projects have various types of housing detached houses, twin houses, townhouses, and condominiums. In Bangkok, the project can provide opportunities for low-income people to have equal housing by the projects located in a cheap location. Some of the sites are no potential to develop for an aging society. Some of them can renovate because the land lot increases the local authority's potential for an aging society.

Analyzed this research was the renovation process in the Baan Eua Arthorn condominium project. The project has created the most difficult to improve renovation only architecture system from a model made especially for low-income buildings, thus providing essential living comfort. The project is necessary to develop the residential unit and public area that have to integrated knowledge. The general area has to analyze in the construction of the existing building. The team residential has to explore interior space spreading across the country, which has the advantage that if there is an improvement, it will significantly enhance the life of the elderly in the future.

\section{Research Methodologies}

The objective of this research is to find guidelines to design and renovate existing low-cost residential buildings to support the aging society in Thailand. Using the following steps for research methodologies are:

\subsection{Collection of Related Documents}

Research related to the design and renovation of low-income housing, low-cost housing and housing of the elderly in Thailand

- Laws and requirements related to the design of comfort facilities for the elderly in Thailand

- Books or textbooks related to universal design $[4,6,7]$.

\subsection{Surveys and Interviews}

Survey the 5-story Baan Eua Arthorn condominium, completed and used in terms of the physical appearance of the building. The 64-room studio standard building model with the most being built was chosen as a case study target. It divides the survey into projects built in the first phase, the middle phase and the current year to find differences that may affect the presentation of guidelines for design improvement.

- Interview the elderly living in the 5-story Baan Eua Arthorn condominium Project on issues of building use, convenience, area requirement and the risk of accidents.

- Interviews with stakeholders involved in project design and construction or the caretaker of the building and the place in the project, such as the National Housing Authority or the government agency who designs the building, condominium juristic person who takes care of the orderliness in the project and companies that were contracted to construct buildings in the past.

\subsection{Data Analysis}

The data obtained from the collection of documents, surveys, and interviews were used to analyze the results of the study.

- Analyze data from related documents to find design standards that can be applied to the case study of the 5-story Baan Eua Arthorn condominium building.

- Detailed construction drawing analysis to find design constraints and supporting factors contributing to the design and improvement of buildings for the elderly society 
- Analyze the data obtained from interviews with the elderly living in the building in order to improve the physical characteristics of the building to suit the lifestyle of the elderly.

- Analyze information obtained from interviews with project stakeholders to cover problems and limitations that may have been overlooked. Including how to apply the building improvement model to be used in the future.

\subsection{Guidelines on Design and Renovation for Case Study Buildings}

The results obtained from the analysis and conclusions of the study will be presented to propose guidelines for designing and improving the 5-story Baan Eua Arthorn condominium buildings to meet the usage and needs of the elderly who live in the building. By applying the principles of design for all and the standards of facilities for the elderly in public buildings according to the laws of Thailand and adapting them as appropriate.

\subsection{Provide Suggestions for Implementing Improvement Guidelines}

Apply the results of the analysis of data obtained from building related personnel to be able to plan for the implementation of the research results in practice taking into account building modification requirements. Construction costs and maintenance burdens

\section{Results}

\subsection{From the Collection of Relevant Documents, It was Found That}

- From the collection of documents related to research to find guideline design and renovation housing for the elderly in Thailand, it was found that most of the research was to propose standards for designing for the construction of all new buildings. As for the design and renovation of the existing residential buildings, it is only in the part of private residences or private projects. For reasons of concerning about ownership of common areas and the submission of building permits, there is a perception that it cannot be altered from a form previously approved by government officials.
In Thailand, there are no regulations on the design of residential buildings to accommodate the aging society. There are only public buildings that must support the use of the elderly, including

(1) hospitals, infirmaries, public health service centers, health stations, government office buildings, state enterprises, state organizations established by law, educational institutions, public libraries and museums, mass transit stations such as airports, train stations, bus stations, and wharves with any part of the building that is open to the public more than 300 square meters.

(2) Offices, theaters, hotels, auditoriums, stadiums, shopping centers, shopping malls of various types with any area of the building providing services to persons exceeding 2,000 square meters.

In Thailand, there is no compulsory passenger elevator for the elderly in high-rise buildings if the tall building is not a public building. All high-rise buildings are regulated only by fire-fighting elevators that can be used during normal times. But if it is closed for people to use, it's not illegal

- Design standards for the elderly in Thailand have been proposed since 2005. Before that, it was just a push for architects and designers in the academic field that made the society more interested and alert.

- Buildings over 4,000 square meters and heights over 23 meters in Thailand are prohibited from renovating buildings by increasing the usable area and increasing the ground cover area from which the construction permit has been granted.

\subsection{Surveys and Interviews}

\subsubsection{Surveys}

The building is arranged in the form of a condominium. The usable area is divided into 2 main parts: the residential area where each room holds a separate title deed and common areas, such as walkways, service sections and various building systems. The 5-story Baan Eua Arthorn condominium building that was selected to be used to design and improve to support the elderly society will be the Baan Eua Arthorn condominium. 5 stories in height, one condominium consists of 64 "Studio Type" rooms (Figure 2), 24 square meters of space in the room, with each room having an undivided empty room, bathroom and balcony. 

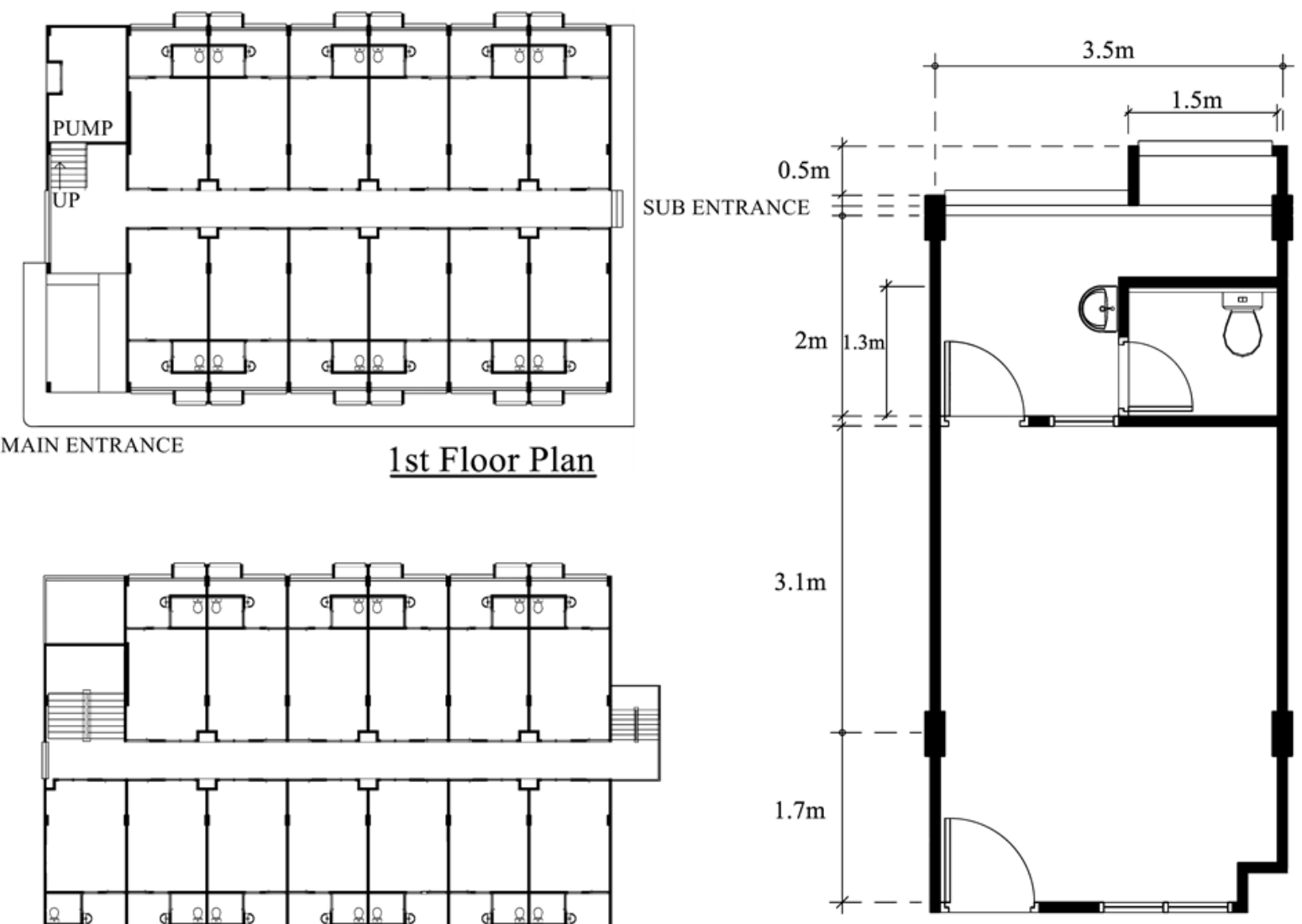

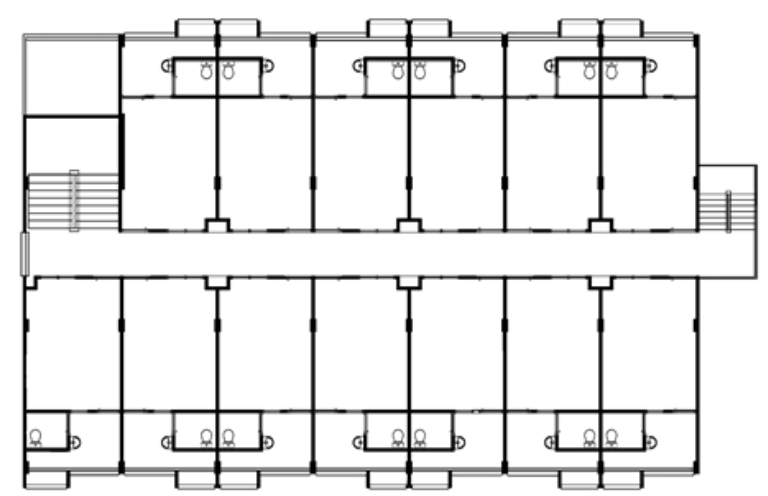

2nd-5th Floor Plan

\section{$\underline{24 \text { sqm Studio Type Unit }}$}

Figure 2. Floor plans and unit details of 5-story Baan Eua Arthorn condominium type 64 units 24 sq.m

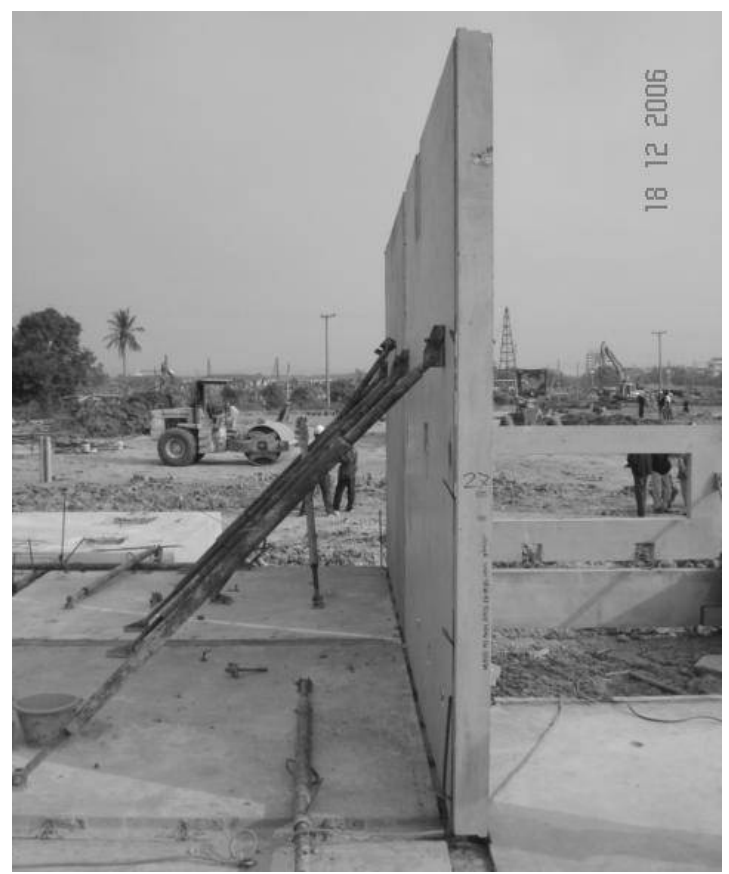

Figure 3. After the beginning of the construction project of 5-story Baan Eua Arthorn condominium in 2003, the main structure was converted to load-bearing wall system in 2006.
Baan Eua Arthorn condominium, a 5-story building, uses the building structure in the form of a column and beam reinforced concrete building, which separates the load-bearing structure from the wall. However, it was found that the actual construction in the latter period has been restructured to achieve the same speed and standard construction for all by adapting to the pre-cast concrete structure using load bearing walls instead of column and beam system (Figure 3), which is the precast wall from the production plant to assemble and install at the job site. Therefore, there are limitations that prevent it from modifying, drilling, chiseling or demolishing the wall because it does not use the general masonry and masonry partitioning method that has the column structure serves to support the load. Therefore, it is a point to be cautious in considering in order to find a way to adjust the condominium to support the aging society.

Electrical work in studio type rooms is sufficient for basic living only. In the empty room, there are two neon lights that are meant to be separated in the sleeping and dining areas. One-way control switch. The television antenna point is placed at the location that corresponds to the internal traffic in the same room as the hotel room. The porch lighting has a radius that covers only the front door, 
not to the corners that may be used for other activities. The electrical outlets are placed in the right corners of the room except in the balcony area behind the entrance door, which is another inconvenient point of use if used on the opposite side. The meter showing the electricity consumption of each room unit is placed next to the main staircase of each floor (Figure 4). The central area lighting arrangement is not much of a problem if the lighting system is fully activated.

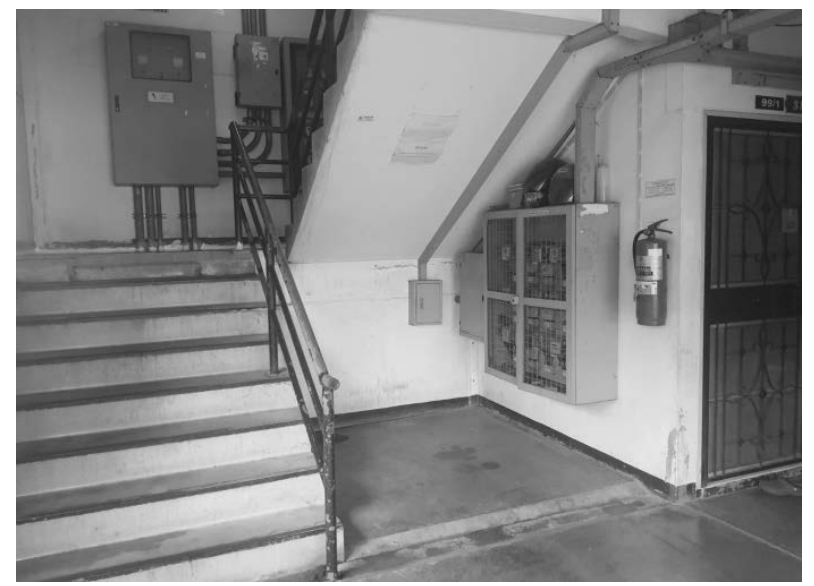

Figure 4. The location of the electricity meter is integrated at the main staircase on each floor.

Each 5-story Baan Eua Arthorn condominium buildings uses a feed down water distribution system, separating the water pump room on the first floor. To pump water from underground water tanks up to the roof and distribute it separately for each room, each floor with various pipe designs to reduce and increase the pressure suitable for the use of residential buildings. In order to enter the room, the water meter will be positioned in front of the room (Figure 5 ), which reduces the number of pipes going back and forth and is convenient for maintenance, but also results in the need to reduce the wall in the front of the room to make the picture. The room plan has corners that need to be solved when placing furniture, various amenities.

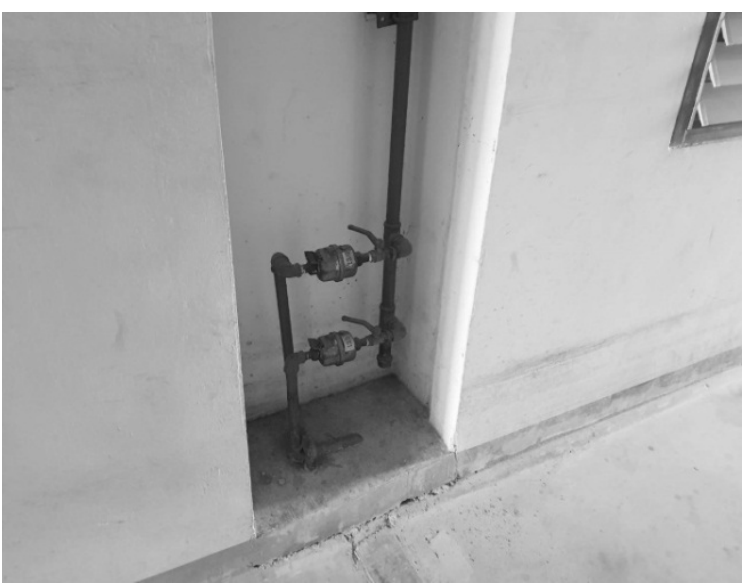

Figure 5. The location of the water meter at the front of the room makes the space inside the room difficult to arrange furniture.

The interesting point of the pipe system that is used is the selection of sanitary ware with a side drain (Figure 6) or perhaps called out back drain unlike sanitary ware in the same building, which has the advantage that the sewer system does not take up the ceiling space of the ground floor room next to it. This allows the repair of the horizontal pipe body to be directly fixed in the problematic room. No need to wait for permission from another room to go in for repairs, similar to the concept and principle of piping installation in Japan that is highly disturbed. But this reduces the load partially because the vertical stand pipes are still shared. As for the sink, the drain pipe is released into the bathroom floor's drain before going into the main sewer system is another point of concern about cleanliness and may cause the bathroom floor to be wet all the time if the water is not drained in time. Wastewater treatment from the database in the construction of a reinforced concrete seepage septic tank. However, this depends on the location of each 5-story Baan Eua Arthorn condominium project where the sanitation system engineers design and prepare a calculation list that permits the use of prefabricated treatment systems of the specified quality. 

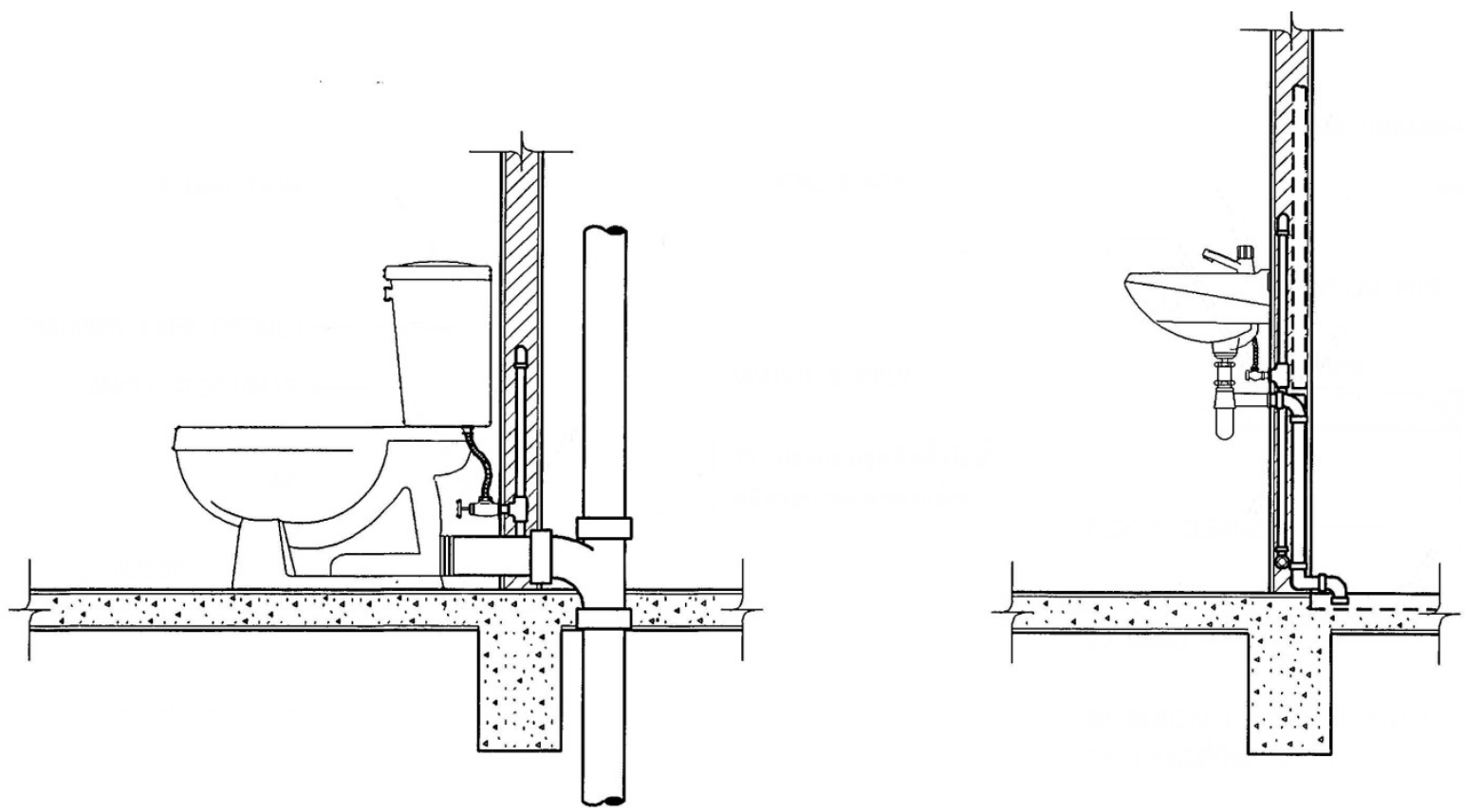

Figure 6. The side pipe type sanitary ware, which is different from the normal style that is the bottom pipe system that is commonly used in Thailand, has the advantage that if there is a leak, it will not affect the downstairs bathroom.

\subsubsection{Interviews}

From the interviews with the elderly living in the 5-story Baan Eua Arthorn condominium project, only in the physical aspect of the building, it was possible to classify the need for improvement from the usage problems of people of this age into two main categories:

\section{(1) External factors}

In this research, it means physical characteristics of the 5-story Baan Eua Arthorn condominium located in the central area of the building. It can be said that it occurs outside the residential area that is the private area of the elderly residents, including

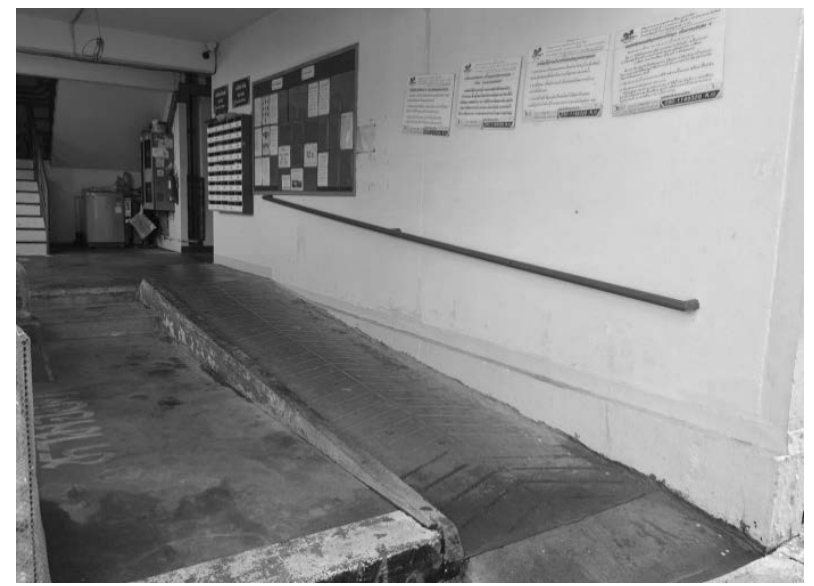

Figure 7. The main entrance of the building on the 1st floor without a barrier to screen outsiders

- Ramp to the building or access to the buildings found that there is a ramp to enter the building only on the 1st floor and the entrance area cannot block the boundary to screen people who come to use the condominium. Affects the safety of both theft and epidemic situations (Figure 7).

- Stairs/vertical traffic consisting of 1 set of main stairs and 1 set of fire escape stairs, no elevators are used. Affects the use of elderly people with the onset of muscle weakness. Osteoarthritis or a neurological disorder that causes inconvenient use and may be at risk of an accident in some cases, it's almost impossible to bring yourself into a room where ownership exists. Until they have to come out to use the common area or the ground floor for living (Figure 8 ).

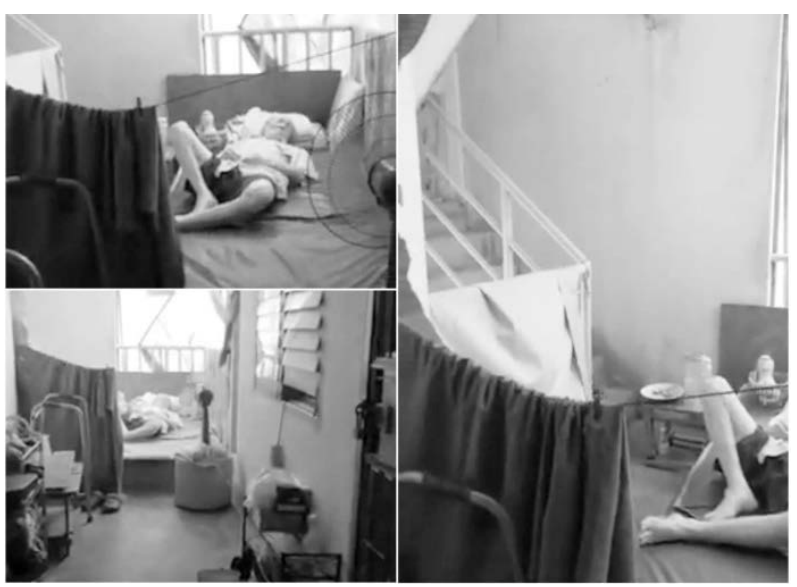

Figure 8. The elderly are unable to walk up and down the high-rise buildings, so they have to come out to use common areas to live, which has raised questions on social media about the quality of life of the elderly and low-income people in 5-story Baan Eua Arthorn condominium. 
- Corridor in front of the room / horizontal traffic although the standard size of the corridor in front of the room is arranged in the style of Double Corridor, but in actual use it is obstructed by various obstacles, including appliances that overflow from the room. Putting shoes in front of the room and iron doors that are additionally installed stacked into the normal room access doors that make the elderly travel inadequately convenient and sometimes accidents can trip and fall (Figure 9).

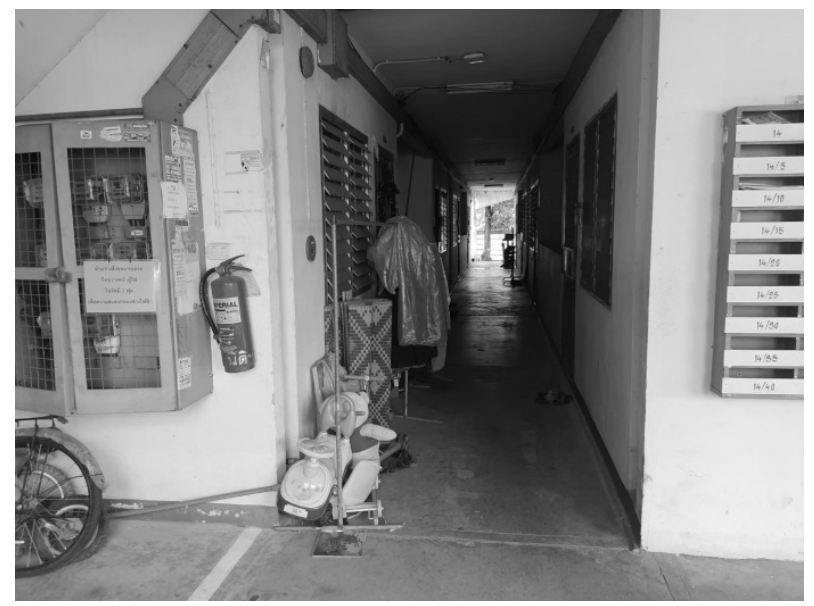

Figure 9. The condition of using the common corridor in front of the room to place shoes and clothes drying rack that overflows from the room should create a sense of coexistence.

\section{(2) Internal factors}

The physical characteristics of the Studio Type living room, which is the private area of the elderly themselves (figure 10). Each room, although the area is the same or similar, but is arranged differently within the space according to the use and the amount of furniture in the room. However, they can be classified according to the activities that occur in the same way as follows:
- Rest area
- Dining area
- Kitchen area
- Working area
- Living area
- Bathroom area
- Washing area
- Tree planting area
- Storage area
- Building system area

Each room that does not have all the elements of use is the same. In surveys and interviews, there was an overlap of usage or collecting applications together. This is because the space per room is limited to only 24 square meters and is often found in congested interior spaces. Difficulty walking affects the assistance of various rescuers if there is an emergency. This mismatched layout of living spaces also greatly affects the lifestyle of the elderly when they need space for their caregivers. It also found that there are frequent accidents in bathroom slippages due to the lack of handrails to help stabilize at risk areas.

\subsection{Data Analysis}

From the collection of relevant documents, surveys and interviews, it was found that there were problems among the elderly living in the existing 5-story Baan Eua Arthorn condominium that should be improved to ensure safety and convenience to the use of the building in 2 parts: the common area and the private area in the room which are detailed in each section as follows:

\subsubsection{Common area}

As the 5-story Baan Eua Arthorn Condominium is a low-cost condominium for low-income people, it was designed using minimum legal standards in designing different areas, which is not a problem for young people who are physically fit. But it creates a lot of difficulties for the elderly. Due to the high proportions of the main staircase and fire escape stairs, it is difficult to walk up and down stairs to the point that it prevents many elderly people from leaving the building unnecessarily and with their legs, no contact with outside society. It also makes it difficult to reach the rescue. The solution is to strengthen the elevator system, which must take into account the building control laws of Thailand.

In terms of the law, the 5-story Baan Eua Arthorn condominium building is not considered a high-rise building and a large building, so an elevator can be added which is classified as a living space other than the one that has been applied for a construction permit. However, it has to be taken into account that the ventilation in the central corridor is a double corridor, which has limited openings that $f$ the position of the elevator is added to block it, will cause ventilation blockages that affect the use of the common area. Ventilation in this corridor is very important for the 5-story Baan Eua Arthorn condominium building because the building is designed so that the rooms have ventilation windows in front of every room in addition to the framed windows outside of the normal building.

\subsubsection{Private area in the room}

All the rooms of the 5-story Baan Eua Arthorn condominium building as the case study will have only the same format for the entire building, namely Studio Type 24 square meters, which is the area size greater than the minimum of condominiums under building control law in Thailand only a little (The minimum is 20 square meters by law). One of the most common problems for the elderly is the safety of using the bathroom, which can be equipped with handrails to help support yourself in dangerous spots and change the direction of opening 
Doors to allow access to help in the event of an accident easily. This is an improvement in the internal area without affecting the outer frame of the condominium and the shared sanitation system.

In terms of space management in Studio Type rooms, there is no proper internal space management, making it difficult to find co-residents or caregivers for the elderly. But with the layout of the room with windows in both the front and the back of the room, the space can be divided into 2 parts (the law in Thailand requires the bedroom area to have a window), which will facilitate finding residents of working age who are interested in the location of the original project of Baan Eua Arthorn condominium, which used to be a suburban area. But with the expansion of the city in the past since the project was built in 2003, it has become an urban area that is close to the source of work Or in the event that the elderly want to hire a caregiver, it can be more convenient if a personal space is arranged for such caregivers.
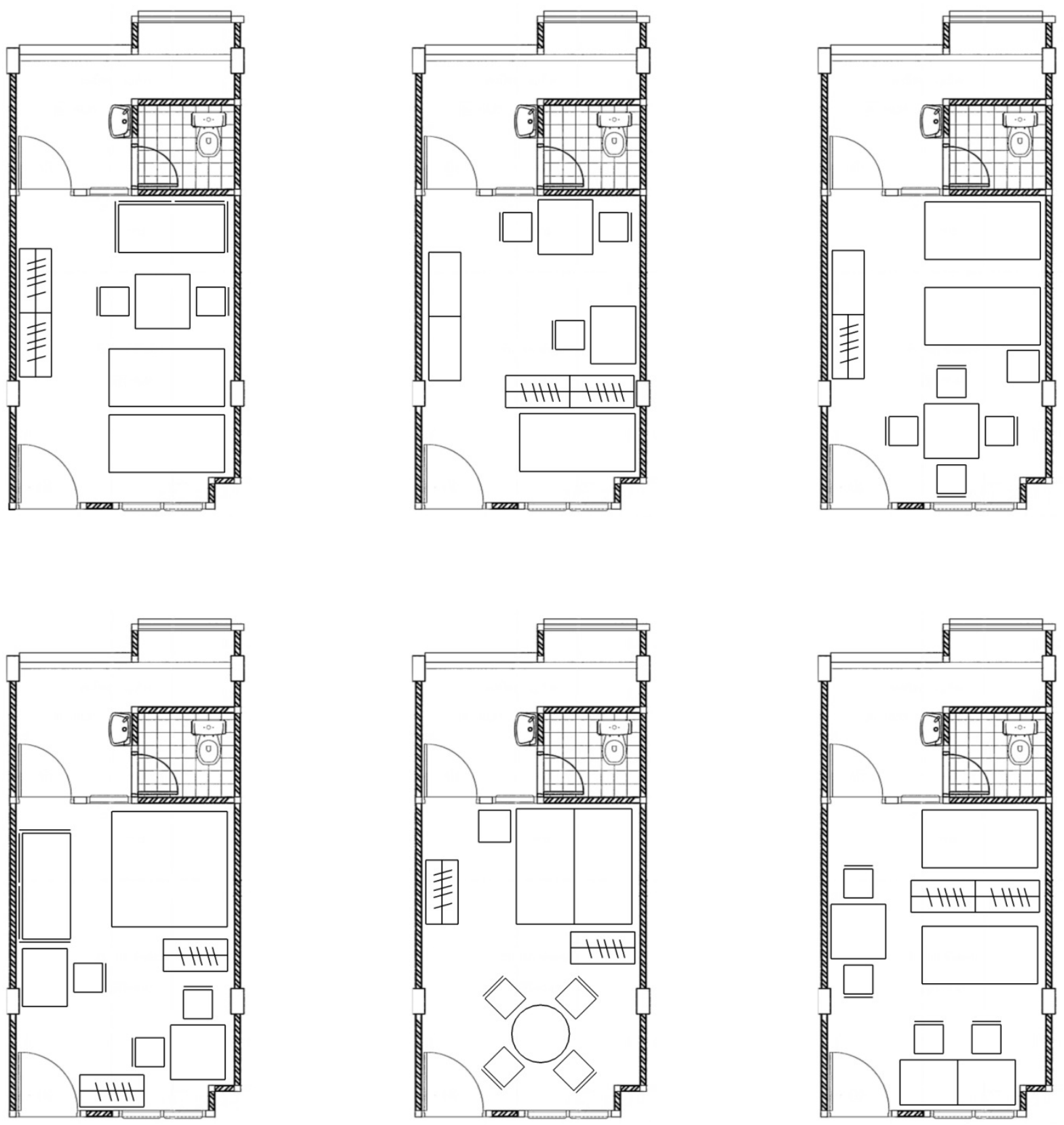

Figure 10. The arrangement of interior spaces is different in each room type, Studio type, size 24 square meters. 


\subsection{Guidelines for the Improvement of Affordable Condominiums for the Elderly}

To enable the elderly residing in low-cost condominiums to be able to live as safe and comfortable as the high-income elderly according to the research objectives from the analysis of building problems as a case study, it led to the creation of guidelines for improving the common areas and private areas in the rooms of the 5-story Baan Eua Arthorn condominium building, details of which are as follows:

\subsubsection{Guidelines for the installation of elevators for the elderly in common areas}

From the considerations of installing elevators for the elderly in the 5-storey building, it is necessary to take into account the form of ventilation in the common corridor in front of the existing rooms (Figure 11) and separating the structure from the original building. There are 4 different ways to position the elevator in the destination position on the main staircase and the fire escape (Figure 12).

- $\quad$ Type 1 passenger elevator, the main staircase is facing the side attached to the building.

- $\quad$ Type 2 passenger elevator, the main staircase facing directly to the corridor.

- Type 3 passenger elevator, fire escape stair position, side facing attached to the building.

- $\quad$ Type 4 passenger elevator, fire escape position facing the corridor.

The method of choosing which type of elevator positioning should be used taking into account the nature of the space surrounding the building as a deciding criterion in choosing the appropriate layout. Because each location of the 5-story Baan Eua Arthorn condominium project is different in the building layout (Table 1). It also has to consider from the form of the main structure of the building that is both built with a column and beam system and load-bearing wall system. The column and beam structure can penetrate the edge of the concrete balcony to connect to the installed elevator because the load of the structure is on the columns and beams. The wall serves as a partition for the use and is a fall protection line only. However, in the recent 5-story Baan Eua Arthorn condominium project, there has been a change to use a precast structure or load-bearing wall system that makes it impossible to modify the concrete wall. In such cases, the elevator must be installed on the side of the fire escape only. This is because the fire escape staircase uses a round tube steel balcony railing that can be dismantled to provide a way to connect to the elevators of the elderly without affecting the strength of the building. In addition, when positioning the elevator into the 5-story Baan Eua Arthorn condominium building, the noise caused by the operation of the machine during use must be taken into account. The elevator is attached directly to the wall of a private room to prevent future disputes.

However, when considering the advantages of each type of elevator installation style, it can be seen that the side-facing elevator attached to the building (Type 1 and Type 3) will take up less space to install because it doesn't have to. Step away from the building to allow for air vents, thereby reducing the impact on the central areas outside the building (Figure 13). But on the other hand, the type of elevator installation facing directly to the corridor (Type 2 and Type 4), although it takes up more installation space, but has advantages if a walkway is built to connect to other buildings. Reduce the cost of installing an elevator system because usually residents of the 5-story Baan Eua Arthorn condominium project or other low-cost condominiums can enter and exit the building without any barriers. This allows the common corridor in the upper floor of the building to be connected without breaking the agreement to use the common area that everyone in the project can walk to connect to each other.

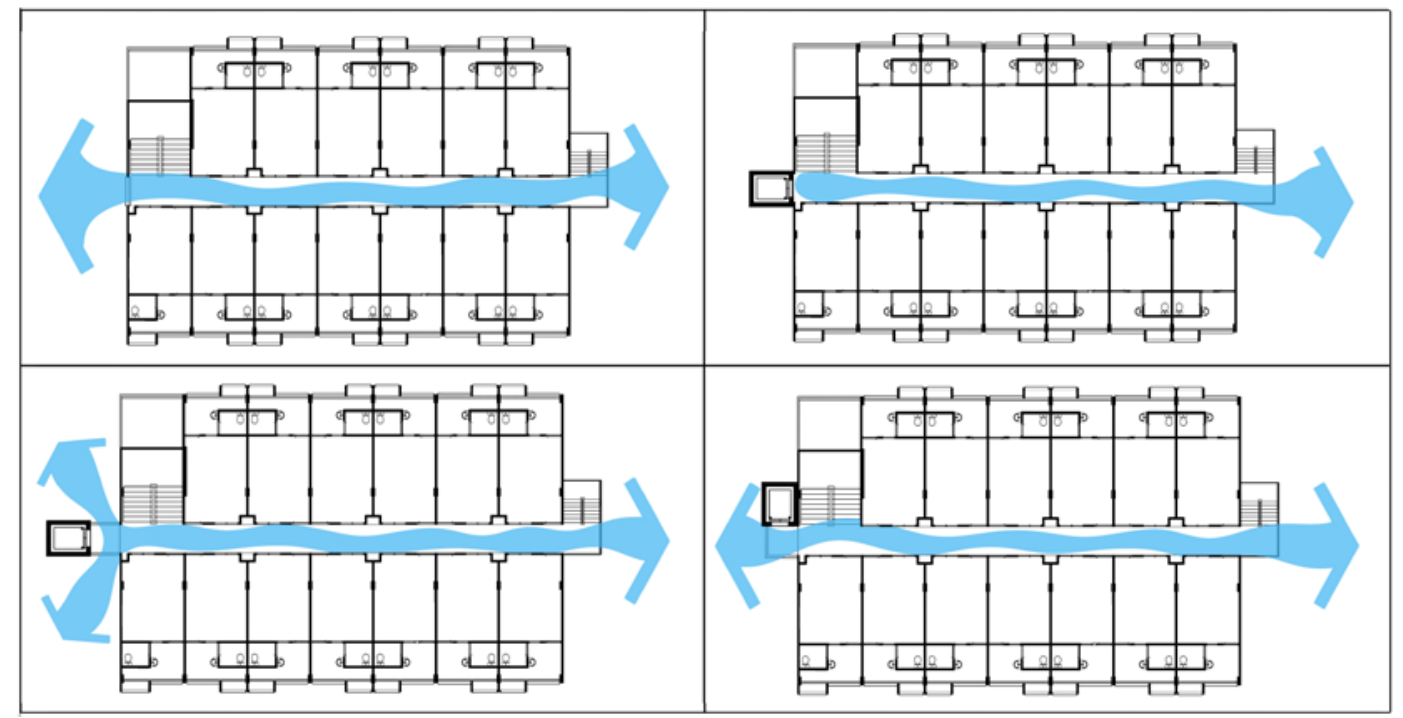

Figure 11. The installation location of the elevator that affects the ventilation and existing voids of the building 
Table 1. The layout of the surrounding area of the condominium that affects the selection of the installation location of the elevator

\begin{tabular}{|c|c|c|c|c|c|}
\hline \multirow{2}{*}{ Entrance } & \multirow{2}{*}{ layout of the surrounding area of the condominium } & \multicolumn{4}{|c|}{ Elevator installation position } \\
\hline & & Type 1 & Type 2 & Type 3 & Type 4 \\
\hline \multirow{3}{*}{ Main } & Distance from footpath beside building $<2 \mathrm{~m}$ & & & \multicolumn{2}{|c|}{ Main Entrance } \\
\hline & Distance from footpath beside building 3-2m & & & & \\
\hline & Distance from footpath beside building 4 - 3m & & & & \\
\hline \multirow{3}{*}{ Sub } & Distance from the fire escape ladder to fence $<4 \mathrm{~m}$ & \multicolumn{2}{|c|}{ Sub Entrance } & & \\
\hline & Distance from the fire escape ladder to fence $5-4 \mathrm{~m}$ & & & & \\
\hline & Distance from the fire escape ladder to fence $6-5 \mathrm{~m}$ & & & & \\
\hline
\end{tabular}

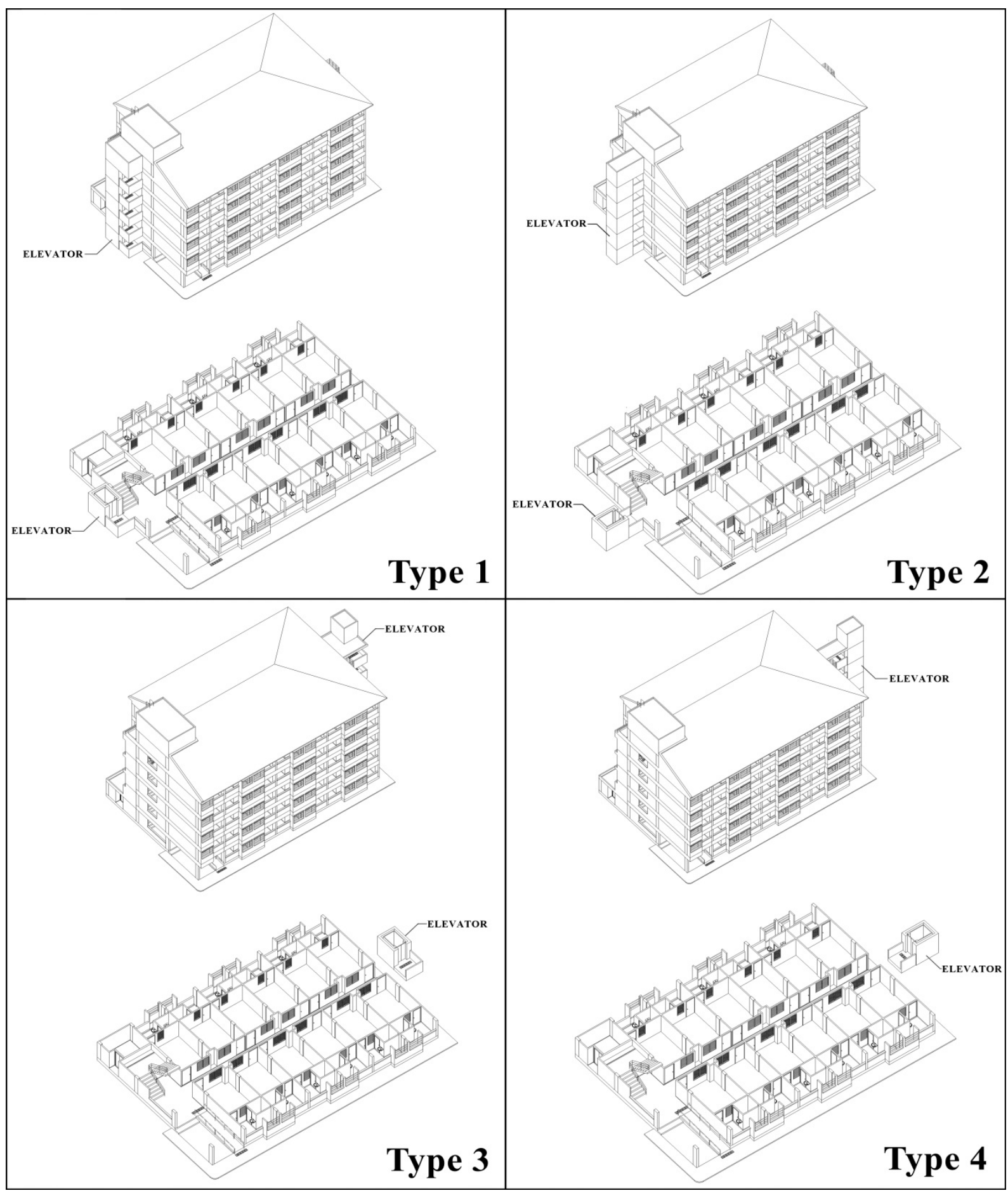

Figure 12. Installation of different types of elevators 

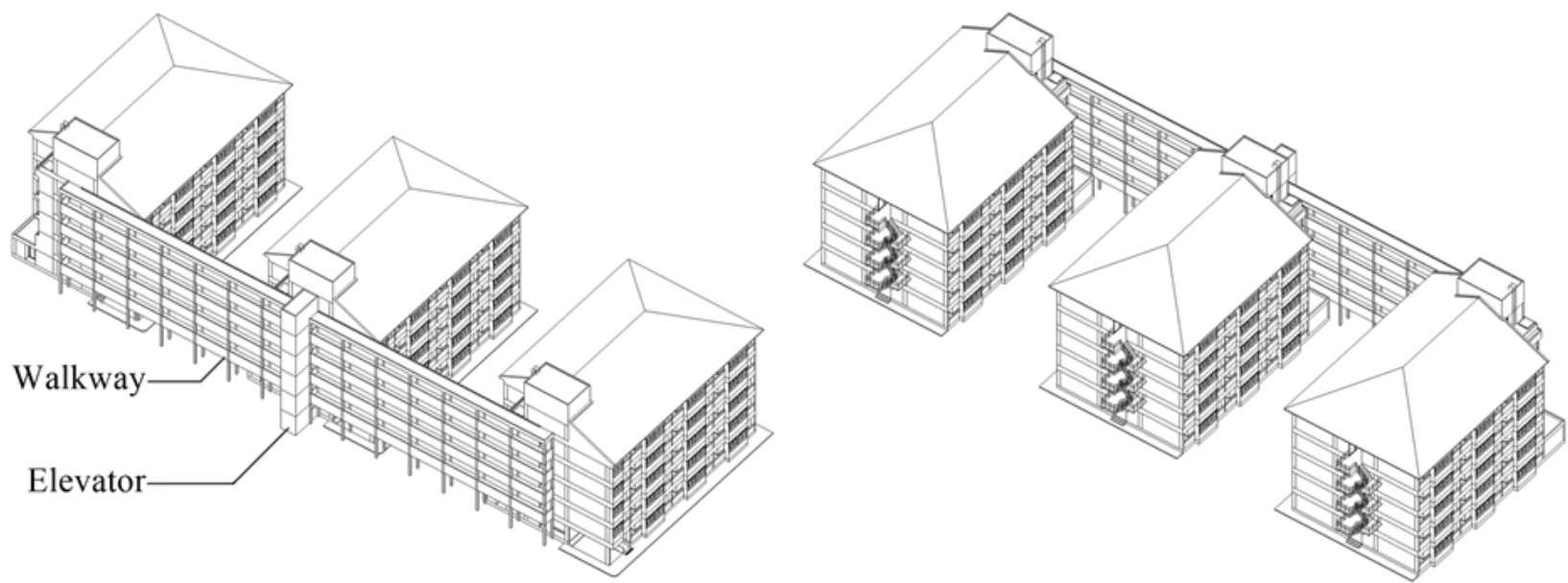

Figure 13. The use of walkways to connect buildings to reduce investment in the installation of elevators
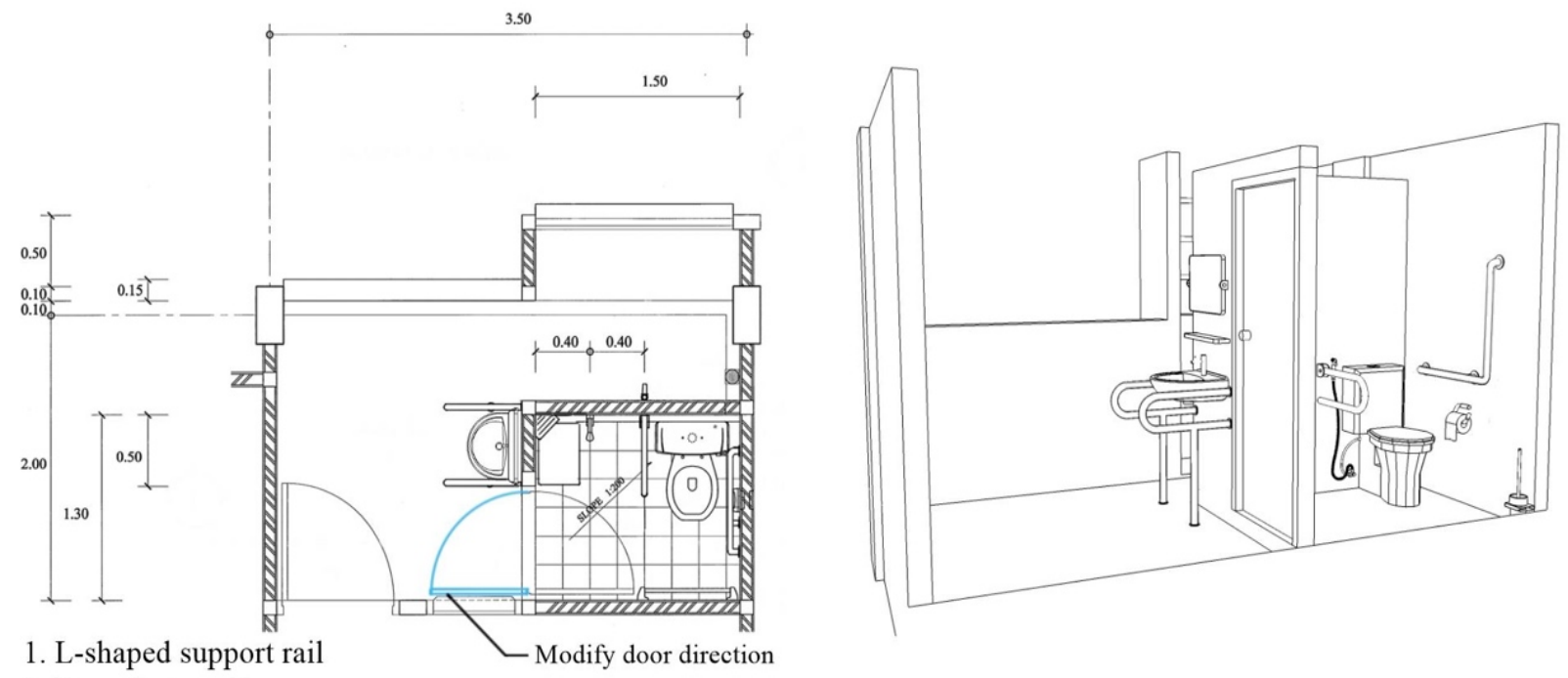

2. Drop down rail

3. Sink handrail

4. Shower chair

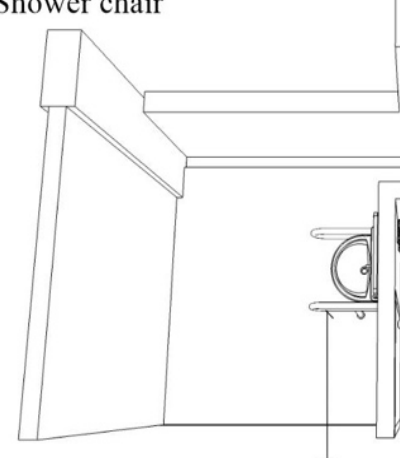

(3)

(4)

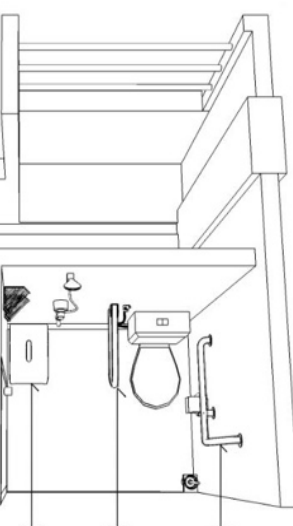

(1)

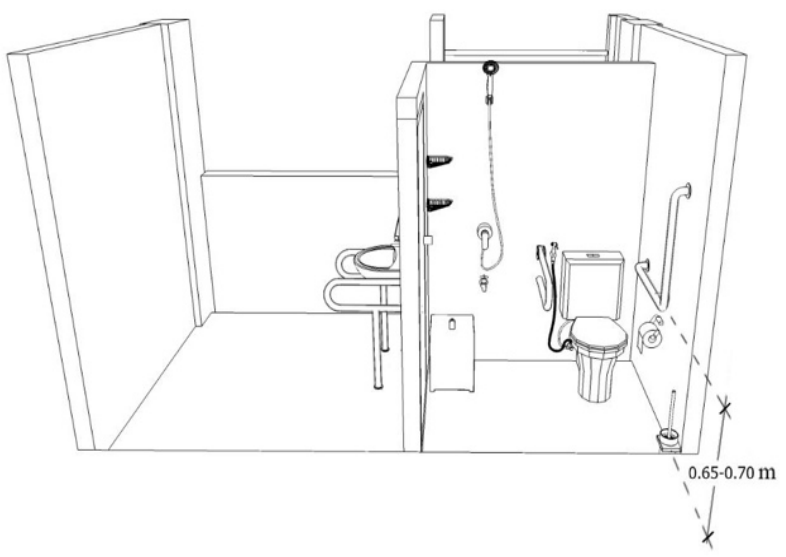

Figure 14. Improving the bathroom with handrails and suggestions for changing the direction of opening the door

4.4.2. Guidelines for Improving Toilets for the Elderly in Private Rooms

In order for the elderly who live in affordable condominiums to be safe from accidents in using the bathroom caused by deterioration of physical fitness according to age in the preparation of improvement guidelines, recommendations on design for all people in Thailand's laws will be applied without modifying the 
building's existing sanitation system that affects the engineering calculation of the building's system work. Overview and cannot expand the bathroom space because the outer bathroom wall has the same status as the outer frame of the building specified in the agreement of the condominium, it cannot be changed in order to preserve the beautiful view of the condominium. Therefore, the guidelines for improving toilets for the elderly in the existing condominiums in the case studies of the research were to improve the use of the bathrooms with handrails to help support themselves in various points, including recommendations for adjust the direction of opening the bathroom door to make the bathroom space more spacious and also make it easier for rescuers to reach in the event of an accident in the bathroom. The guidelines for improving the bathroom for the elderly in private rooms will improve the risk of accidents and make it easier to use as follows (Figure 14).

- Install L-shaped handrails on the side of the wall around the toilet bowl.

- Install handrails that can be lifted up and down at the toilet bowl.

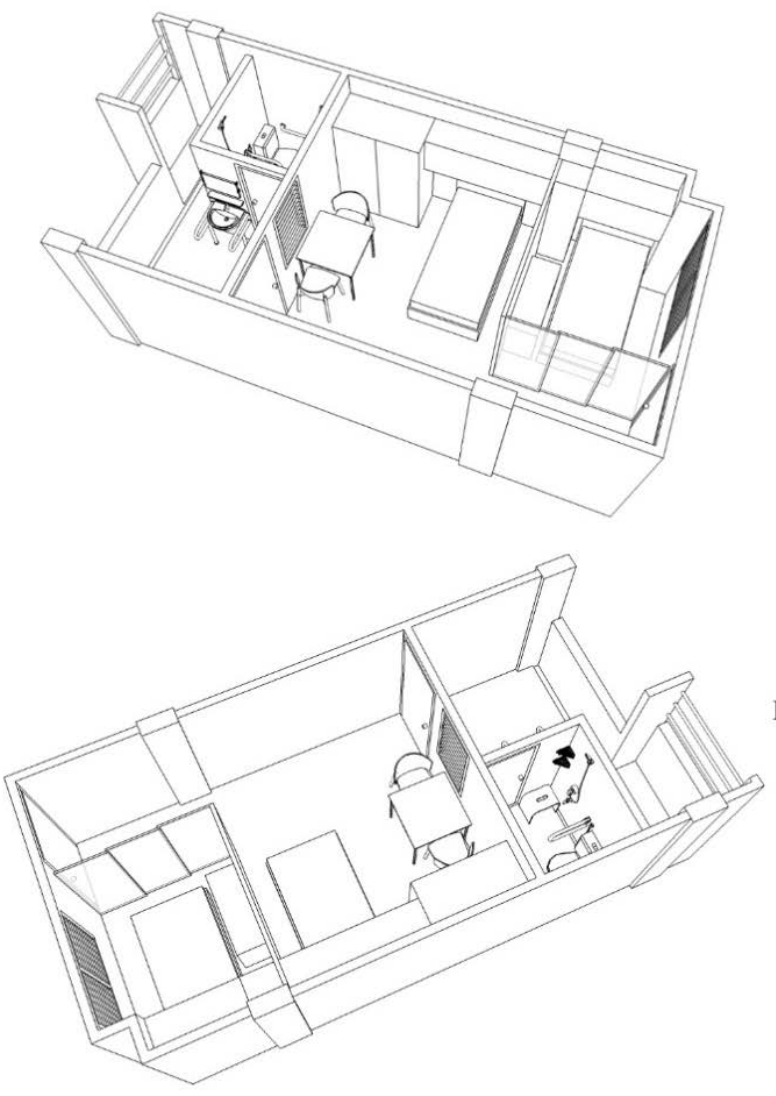

- Install handrails around the sink.

- Add a shower chair at the shower stand.

- Change the direction of opening the door to the bathroom to open.

\subsubsection{Guidelines for Space Management in Private Rooms} for Co-residents or Caregivers of the Elderly

In order for an affordable condominium that is a case study to support the needs of the elderly in the event that a co-resident or caregiver is required, the room type is a Studio Type with supportive factors that come from the form of the window. Originally having both the front and the back of the room, the space can be divided into two while still being ventilated according to Thai law that states that bedrooms must have windows that can be ventilated. In order to divide the usable space effectively, the zoning of the internal corridor is in the direction connecting the entrance door to the room and the exit door at the balcony. The arrangement of the corridors in this manner will make the interior space tidy and divide the sub-rooms for the best co-residents or caregivers of the elderly (Figure 15).

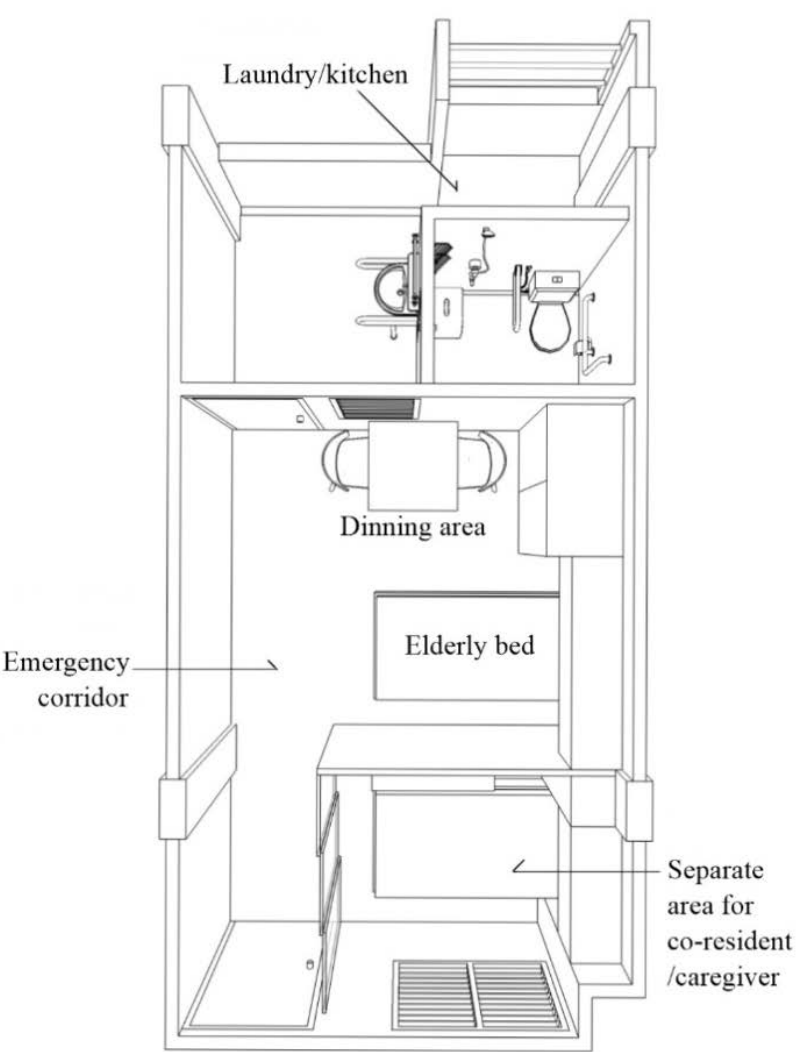

Figure 15. Preparing areas for co-resident and elderly caregiver 


\subsection{Provide Suggestions for Implementing Improvement Guidelines}

Regarding the budget to improve the common area, it proposes to install additional passenger elevators, which will cost about 1,300,000-1,800,000 baht that depends on the specification of the elevator and the structure chosen in each project location. Whether it is a reinforced concrete structure or a steel structure, the budget for renovating the bathroom with support is about 7,400 baht per unit. As for the internal usable space, can use furniture layouts or easy-to-install materials such as curtains or room dividers according to budget and preferences of the owner of the unit.

The improvement of the common areas will be in the National Housing Authority's plans to bring the existing condominiums that are not sold out to support the elderly society in the form of rent. The projects that have been built and occupied for a long time as a case study, it is possible to find funding from the government to support the elderly by creating a project to present from the condominium juristic person. As for the private spaces in the unit, it is also possible to find individual government funding that is set up to improve the elderly's housing without having to build a new building, which sets a limit for people of more than 22,500 baht [1]. The project is enough for the bathroom renovation guidelines in the rooms that have suggested improvement.

\section{Conclusions}

Finding guidelines design and renovate a long-established low-cost condominium to support an aging society so that the elderly can comfortably and safely live in the same accommodation as one way to help solve the housing problem inadequate elderly in the future. Especially among the low-income elderly in Thailand who lack the budget for shelter in old age. In the research, a number of case studies of low-income condominiums have been built in the same way since 2003 by the National Housing Authority called "5-story Baan Eua Arthorn condominium", which is a low-cost condominium project spreading in various parts of the country. In the study, relevant documents were collected building construction and surveying the projects that have been completed and used for a long time together with interviews with the elderly who live in this type of building, it was found that the 5-story Baan Eua Arthorn condominium, a low-cost condominium, was built to serve the target group of low-income people in working age who are still physically strong are different from the elderly, making it difficult for the elderly or those who start to become elderly in the building. Problems caused by the use of the elderly are both in common areas and private rooms.

Problems in the common areas are caused by the lack of a vertical travel assistance system that makes seniors living in high floors experience problems walking up and down due to physical disabilities. Some of the elderly in the building choose to walk up and down the building as necessary, depriving them of social interactions outside. Some elderly people with illnesses have to leave their rooms to live in the ground floor common area because they can't get up and down the building easily. Thus causing the need to improve the building to have an elevator system. When examining the legal requirements in Thailand, it was found that the 5-storey Baan Eua Arthorn condominium, which is a case study, can still be improved to increase usable space at this point. From the study of the structure of the building, it was found that the condominium that was the case study was built in column and beam in the first period. It was later converted to a load-bearing wall for reasons of speed and cost of construction. This affects the improvement of the building with the installation of the elevator system because the connection point with the elevator system that meets the main staircase location requires the removal of the wall to connect the traffic, but it can be avoided to use the elevator connection by using the area next to the fire escape stairs that do not need to divide the wall in the load-bearing part. However, in choosing a location to install an elevator to facilitate the elderly in the 5-storey Baan Eua Arthorn condominium building, it must also take into account the conditions of the surrounding area of the building in addition to the impact of the elevator position that may cause ventilation in the area. The corridor in the middle of the building changed. From such limitations, there was a choice of approaches to improve the traffic system in the vertical building with 4 types of elevator systems that are related to the surrounding conditions of the 5-storyy Baan Arthorn condominium building, which differ in each project location.

The problem of private space in the room related to the elderly from the study of related documents, building construction, survey of room conditions in which the elderly actually used it and interviews with the elderly in the 5-story Baan Eua Arthorn condominium building revealed that all rooms in the building, with an area of approximately 24 square meters each, were designed to be "Studio Type" rooms with a separate bathroom on the balcony. From long use, besides the deteriorating condition, there are frequent accidents in the bathroom and it is difficult to get help from the cramped interior space. When considering the improvement to expand the usable space, there is a problem of the agreement on the exterior wall frame of the condominium that prohibits modification from the overall picture that has been asked for a construction permit. Therefore, the design and improvement guidelines must be drawn from the usable space in the original bathroom by reducing accidents in use and making the elderly more comfortable by adding handrails to help support themselves at various points of risk. Change your shower posture from standing to sitting 
in a safer shower chair. Including solving the problem of access to help rescuers in the event of an accident in the bathroom that often finds the direction of the door opening causing collisions with an elderly person who fell on the cramped bathroom floor by changing the direction of opening the bathroom door outside instead. As for the main space in the room, after a long period of use during the working age, when the old age is filled with so many appliances that it is difficult to divide the space for the co-resident. In the past, when the 5-story Baan Eua Arthorn condominium projects were built, they were often located in the suburbs, but after a very young age, the city has expanded to cover low-cost condominiums. It has begun to be accessed from the public transit system, the rail system that has changed the potential of the 5-story Baan Eua Arthorn condominium project in various locations. There is a growing demand for people of working age, which is an opportunity for the elderly living in the old condominium to find co-residents or caregivers. This is in line with the needs found from surveys and interviews to renovate the old rooms that have been in existence for a long time to make room for this activity. Considering the layout of the Studio Type rooms that use a central corridor with a double corridor at the ventilation windows of the rooms in both the front and the back of the room, the interior space can be divided to separate the sub-rooms in accordance with the building regulations in Thailand that require the bedroom space to have ventilation windows, allowing the space to be allocated for co-residents or caregiver for the elderly.

In terms of bringing the cost-effective condominium renovation approach to practical use, a case study of the 5-story Baan Eua Arthorn condominium can be presented to the government agencies regarding the care of the elderly in the part of the improvement in the common areas that are being improved. To have an elevator system installed to aid in traffic, but in terms of annual maintenance, it must be a budget that comes from collecting the common fee of the condominium itself. The awareness of elevator sharing must be encouraged for reasons of improvements that increase comfort and increase the resale price of the rooms in the future if they change hands. Renovating private spaces in rooms in Thailand has a budget to help elderly people in the event that the renovation is not a new construction, so the guidelines from this research can be used to propose for that budget. Both in terms of improving the bathroom for the elderly and allocating space for co-residents or caregiver for the elderly.

\section{Recommendations}

In proposing a way to improve the existing low-income condominiums for the aging society, an approach to enhance the architecture to suit the changing body of the elderly to modify the physical appearance of the building to have facilities and safety for the age range. The uncontrollable factors need to rely on the cooperation of the residents in the condominium, the behavior of using the common areas. In particular, the encroachment of the common area from the unit made the corridors inside the building narrow. The researchers hoped that the renovation of the existing condominium would result in a more livable building with the elderly and general residents. The latter are not yet old enough to feel the quality of life is better until there is a good sense of unity in organizing common areas in order. Do not view their residence as just a low-income condominium that has been in use for a long time and is waiting to deteriorate over time.

\section{REFERENCES}

[1] Department of Older Person, "Procedures for implementing the project to optimize the environment and facilities for the elderly to be suitable and safe," in Guide for the implementation of the project to optimize the environment and facilities of the elderly to be suitable and safe for the fiscal year 2021, DOP, 2021, pp 5-15.

[2] Kasikorn Research Center, "How to answer of the Elderly housing business", Econ Digest, https://kasikornresearch.co m/th/analysis/k-social-media/Pages/elderly-FB-200820.aspx (Accessed Feb. 2, 2021)

[3] Knowledge Management Working Group National Housing Authority 2016, "Organizing the environment inside the house and around the house for the elderly group who stay in the house," in Development of a new type of housing for the elderly, NHA, 2016, pp. 17.

[4] Neufert, Ernst, P. Neufert, B. Baiche, N. Walliman, "Building for Disabled People," in Architects' data, $3^{\text {rd }}$ ed, BSL, 2000, pp. 298-301.

[5] T. Jarutat, "Direction of Thai Elderly Development," Seminar on Residential Development Direction to support an aging society, Government Housing Bank, Aug. 25.

[6] T. Jarutat, "Recommendations on the Distance and Suitable Area Size," in Recommendations for the design of environments and shelters for the elderly, DOP, 2016, pp. $4-16$

[7] T. Jarutat, “Universal Design Criteria,” in Universal Design, $1^{\text {st }}$ ed, CU Press, 2018, pp. 107-148. 